\title{
AN EMPIRICAL ANALYSIS OF THE EFFECT OF ECONOMIC GROWTH ON STOCK MARKET PERFORMANCE: A STUDY BASED ON SRI LANKAN ECONOMY
}

\author{
Mathuranthy Amaresh \\ Faculty of Management Studies and Commerce \\ University of Jaffna, Sri Lanka \\ Email: mathu_019@hotmail.com \\ * Anandasayanan.S \\ Department of Financial Management \\ University of Jaffna, Sri Lanka \\ E-mail: sayananakshi@yahoo.com
}

\begin{abstract}
The economic growth of a country is a dominant factor in determining how prosperous a nation is. Finance is an important element of economic growth. Stock market is also playing a vital role in promoting the industry and commerce, which affects the economy of the country. Smooth functioning of a stock market will enable a country economically stabilized. Therefore the economists and financial analysts are paying more attention on the activities of stock market. The All Share Price Index is used to measure the performance of share market. The performance of stock market is being influenced by various factors, and economic growth is one of them. The sampling period of this study was from 2002 to 2018. Investigating the effect of economic growth on stock market performance by employing time series analysis is the objective of this study. The economic growth which was measured by GDP per capita was considered as independent variable and All Share Price Index (ASPI) was considered as dependent variable. Hypotheses were tested using correlation and regression analyses. The findings of regression analysis revealed that the economic growth has positive and significant impact on the performance of share market. That is, approximately $83 \%$ of the changes in the share market performance are described by the economic growth. The correlation analysis indicated that there is strong and positive correlation
\end{abstract}


between economic growth and stock market performance. Economic growth plays a dominant role in accelerating the performance of stock market. The nations which have stable macro-economic environment will undergo better and increased share market performance. Appropriate economic policy amendments or abolition should be made to boost up Sri Lankan economy.

Keywords: All Share Price Index; Economic Growth; Stock Market Performance

\section{Introduction}

The stock market is known as a primary indicator of evaluating the economic growth of a country. Sri Lanka experienced economic vulnerabilities in 20183.2 per cent was the real GDP growth in 2018 but it was 3.4 per cent in 2017. However, the economic performance of Sri Lanka in 2018 is not satisfied as its regional peers, countries in South Asia and Southeast Asia have higher economic growth. Though the Sri Lankan stock market has begun to grow after the end of local war in 2009 and it was positioned as the second best performing stock market in the world by Bloomberg. The all share price index was 3385.55 in 2009 and it was significantly increased to 6635.87 in 2010 . It showed a declining trend until 2013 and all share price index recorded a best performance of 7298.95 in 2014. The stock market performance has been fluctuating and reached 6052.37 in 2018. This scenario has changed considerably at the moment, diverting the attention of investors somewhere else. Hence the Colombo stock market has put itself on a slower path due to macro-economic forces. The decrease in the economic growth has been identified as the key and dominant indicator which impacts on Sri Lankan All Share Price index that is, changes in this indicator leads to repercussion in the entire economy. The stock market enhances the domestic savings by setting financial instruments available to savers to diversify portfolios. A stabilized stock market allows investors to diversify unsystematic risk. According to Athapathu, \& Jayasinghe (2010) the performance of stock market is an influential factor for economic growth in Sri Lanka. Observing the impact of economic growth on share price index in Sri Lanka would benefit not only portfolio managers, but also for economic policy makers. Moreover, this research study investigates the controlling mechanisms of stimulating the economic growth in Sri Lanka that would stabilize the Sri Lankan economy. 


\section{Research Problem}

It is an undeniable fact that economic growth has significant impact on the performance of stock market. Lower economic growth will definitely cause a stock market volatility which could potentially destabilize the economy and make it inefficient. It is an inevitable responsibility of every Sri Lankan economists and policy maker to make polices that reduce market volatility. In 2018 the benchmark All share price index has made a $4.9 \%$ loss but it gained 2.3\% in 2017. Market was less active in 2018 in terms of turnover compared to the previous year. As stated above, nowadays the Sri Lankan economic growth is experiencing dwindling and frequent fluctuations. The Sri Lankan economic growth was 3.4 per cent in 2017 and it was decreased to 3.2 per cent in 2018.

The results of the previous studies are contradictory with regard to the association between economic growth and stock market performance. Rasheedat and Onabote (2017) found that the all share index had a significant but negative relationship with economic growth but contradictorily Silva, Perera and Silva (2017) found a strong and positive relationship between stock market performance and economic growth of Sri Lanka. Therefore, there is a requirement to confirm whether economic growth and stock market performance are positively correlated or not. It is also crucial to find out to what extent economic growth is impacting on all share price index in recent years. Therefore, the constant need for the study of economic growth and all share price index is necessarily required to accelerate the Sri Lankan economic growth, to reduce the market volatility and to stabilize Sri Lankan economy. Based on the above factors the problem statement of the study is defined as follows.

"To what extent the economic growth impacts on share market performance in Sri Lanka". Studying these economic factors will be really beneficial and important since it will provide accurate guidance towards potential investment decisions in Colombo Stock Exchange.

\section{The Objective of the Study}

Finding out to what extent economic growth impacts on the stock market performance and the relationship between economic growth and stock market performance in Sri Lanka are the objectives of this study. 


\section{Significance of the Study}

The Colombo stock market is playing a vital role in promoting the economic prosperity. It has been observed as a significant component in Sri Lankan financial sector because it offers shares and corporate bonds, companies can raise money. Further, this study will be beneficial for the investors to analyse the financial achievements of the companies, it will also be supportive for them to make profits through capital gains, and earn money through dividends. In the long term, it helps in capital formation and economic growth for the country. The ultimate intention of this study is to figure out exactly what relationship exists between economic growth and stock market performance. This investigation will be beneficial for the investors, portfolio managers, policy makers etc.

\section{Data Collection and Sampling Method}

This study used secondary data for the analysis. Annual data from 2002 to 2018 was employed in the study. The required data of stock market performance was collected from Colombo Stock Exchange website and the data of economic growth was collected from department of census and statistics.

\section{Literature Review}

The theoretical underpinnings and empirical studies related to economic growth and stock market performance is presented in this section.

\subsection{Theoretical Underpinnings}

Underpinning theories on economic growth are discussed from different perspectives.

\subsubsection{Endogenous Growth Theory}

It is an economic theory that argues that economic growth is generated from within a system as a direct result of internal processes. That is, it confirms that the economic growth (by means of the development of new forms of technology and efficient and effective means of production) will be led by enhancement in a nation's human capital. 


\subsubsection{Post Keynesian Growth theory}

This theory postulates that economic growth depends on policies to increase investments through savings and capital accumulation. It also implies that economy growth will be decreased when there is plenty supply of labour with limited physical capital investments

\subsubsection{The Neoclassical Growth Theory}

It is also known as the Solow growth model which was postulated by Robert Solow as an extension of the Harrod-Domar model. The theory assumes, diminishing returns of factor inputs (labour and capital), where growth per unit increases with growth per unit capita at a diminishing rate. According to this theory, economic growth would be attained with the sufficient amount of these factors.

\subsection{Empirical Review}

Gamlath (2019) carried out an investigation on share trading and economic growth in Sri Lanka employing multiple regression models using data from 1995 to 2014. The growth of all share price index, market capitalization growth and market turnover growth were used as independent variables whereas the GDP was the depending variable. inflation rate and exchange rate were used as control variables. A positive relationship between share trading operations and economic growth in Sri Lanka was explored by this study.

The causal relationship between the performance of share market and economic growth in Sri Lanka was examined by Athapathu and Jayasinghe (2012) from the year 1997 to 2008 by employing co-integration analysis, error-correction mechanism and Granger causality tests. The variables were All Share Price Index and real and nominal GDP. A unidirectional causal relationship was found out by this study. Further, the association between the performance of share market and economic growth in Sri Lanka was analysed by Silva, Perera and Silva (2017). This study used simple regression model and correlation analysis and the findings revealed a strong and positive association between variables.

The relationship between the development of stock market and economic growth in Bangladesh, India, Pakistan, Sri Lanka and Nepal was researched by Mukit, 
Uddin, Islam and Arif in 2014. This study collected secondary data of 15 years from 1996 to 2010. The study incorporated market capitalization, total value of stocks traded, stock turnover ratio and volume of the stock market determined through the total number of companies listed in the stock exchange. The linear log model was employed and the findings found out that stock market significantly impacts the economic growth of selected five SAARC countries.

The causal relationship (short run effect and long run effect) between stock market and economic growth in Nigeria was investigated by Rasheedat and Onabote (2017). The ADF unit root test, Johansen co-integration test OLS, and pairwise granger causality methods were chosen as research methodologies. The OLS results showed that share market performance had a significant and negative relationship on the economic growth.

The relationship between the development of the stock market and economic growth in Sri Lanka was examined by Jahfer and Inoue in 2014 by using quarterly data from 1996 to 2011. The Augmented Dickey Fuller (ADF) test, Johansen cointegration tests, and Vector Error Correction Model were employed in this study for the data analysis. As per the VECM results, there is unidirectional causality from stock market development to economic growth. It was recommended to enhance the performance of share market as it leads to the economic growth in Sri Lanka.

Nijam, Ismail and Musthafa (2011) researched about the effect of macroeconomic variables on the performance of stock market. Interest rate, GDP, inflation, balance of payment and exchange rate were the independent variables. The sampling period was from 1980 to 2011. This study employed correlation and multiple regression techniques were employed. A significant and positive relationship was found between all share price index (ASPI) and exchange rate. There is positive and significant association between GDP and all share price index whereas it was also found that interest rate also has positive and significant correlation with stock market performance. In contrast, inflation is negatively and significantly associated with share market performance while balance of payment is not significant in the model therefore, in general, it is found that macroeconomic factors significantly influence the movement of all share price index, the ASPI, the prominent parameter of Colombo stock exchange. 


\section{Conceptual Framework}

The researcher has formulated the following conceptual model.

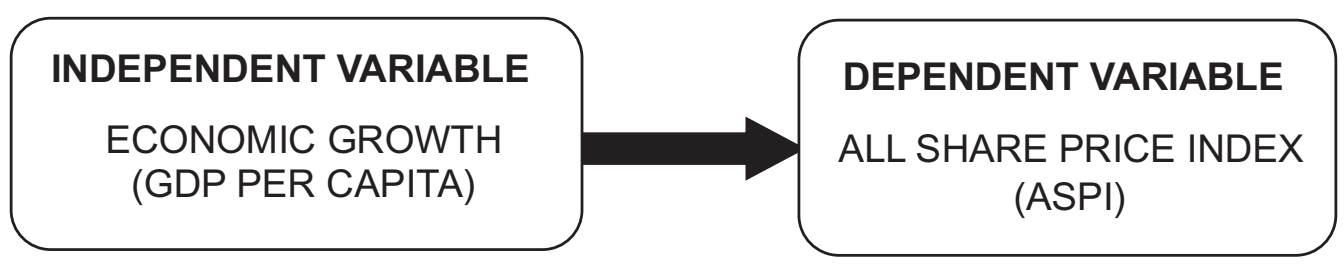

\section{Figure 1 : Conceptual Model}

Source: Developed by researcher

GDP per capita is the independent variable and ASPI is thedependent variable.

\section{Definition of Variables}

\section{Economic Growth}

Economic growth is an increase in the amount of goods and services produced per head of the population over a period of time. GDP per capita is used as the proxy of Economic Growth.

\section{All Share Price Index}

A group of stocks are being put together in a standard manner for the provision of useful window into a sector market's performance at a glance.

\section{Hypotheses of the Study}

The hypotheses are stated below.

H1: There is relationship between economic growth and stock market performance.

$\mathrm{H} 2$ : Economic growth impacts on stock market performance.

\section{Results and Discussion}

The research employed correlation analysis to find the association between independent and dependent variables, regression analysis to examine the impact of independent variable on dependent variable, descriptive statistics, unit root test 
as the study included time series data and residuals normality test to check the model fitness. These methodologies have been employed by the previous researcherssuch as Gamlath (2019), Silva, Perera and Silva (2017) and Nijam, Ismail and Musthafa (2011).

\subsection{Descriptive Statistics}

Descriptive statistics represents the basic features such as means, maximum, minimum, standard deviation, skewness and kurtosis of the variables.

Table 1: Results of Descriptive Statistics

\begin{tabular}{|l|c|c|}
\hline & ASPI & $\begin{array}{l}\text { GDP PER } \\
\text { CAPITA }\end{array}$ \\
\hline Mean & 4268.686 & 2520.294 \\
Median & 5643.000 & 2370.000 \\
Maximum & 7298.950 & 4104.000 \\
Minimum & 815.1000 & 858.0000 \\
Std. Dev & 2373.224 & 1233.037 \\
Skewness & -0.213299 & -0.002513 \\
Kurtosis & 1.338358 & 1.396596 \\
Jarque-Bera & 2.084654 & 1.821075 \\
Probability & 0.352633 & 0.402308 \\
Sum & 72567.66 & 42845.00 \\
Sum Sq. Dev. & 90115045 & 24326074 \\
\hline
\end{tabular}

Table 1 represents the results of descriptive statistics. The results showed that all share price index has a mean value of 4268.68 with minimum value of 815.1, maximum of 7298.95, skewness value of -0.213299 and kurtosis value of 1.33 . The standard deviation is 2373.224. Economic growth (GDP per capita) has a mean value of 2520.29 , minimum of 858 , maximum of 4104 skewness of 0.0025 and kurtosis of 1.39. The standard deviation is 1233.037. 


\subsection{Correlation Analysis}

The correlation analysis is employed here to analyse the strength of the association between the variables.

\section{Table 2: Results of Correlation Analysis}

\begin{tabular}{|l|l|l|}
\hline $\begin{array}{c}\text { Correlation } \\
\text { Probability }\end{array}$ & ASPI & $\begin{array}{l}\text { GDP PER } \\
\text { CAPITA }\end{array}$ \\
\hline ASPI & 1.000000 & \\
GDP PER CAPITA & $\ldots \ldots$ & 1,000000 \\
& 0.913115 & $\ldots \ldots \ldots \ldots$ \\
\hline
\end{tabular}

Table 2 clearly indicates the existence of the relationship between the variables economic growth and stock market performance. The results of correlation analysis reveals that the coefficient value between the economic growth and the all share price index is 0.913115 whereas the $P$ value is 0.000 which is significance at $1 \%$. Astrong and positive relationship was figured out between economic growth and share market performance hence hypothesis is supported with this results. It means when economic growth increases the performance of stock market will also increase.

\subsection{Results of Regression Analysis}

Regression analysis is used in statistics to figure out the trends in research data. OLS regression was employed in this research study to figure out the impact of economic growth on the share price index. 
Table 3: Results of Regression Analysis

\begin{tabular}{lccll}
\hline \hline Variable & Coefficient & Std. Error & t-Statistic & Prob. \\
\hline \hline C & 160.6577 & 565.2343 & -0.284232 & 0.7801 \\
GDP_PER_CAPITA & 1.757471 & 0.202610 & 8.674178 & 0.0000 \\
\hline \hline R-squared & 0.833779 & Mean dependent var & 4268.686 \\
Adjusted R-squared & 0.822698 & S.D. dependent var & 2373.224 \\
S.E. of regression & 999.2999 & Akaike info criterion & 16.76212 \\
Sum squared resid & 14979004 & Schwarz criterion & 16.86014 \\
Log likelihood & -140.4780 & Hannan-Quinn criter. & 16.77186 \\
F-statistic & 75.24136 & Durbin-Watson stat & 1.298313 \\
Prob(F-statistic) & 0.000000 & & & \\
\hline \hline
\end{tabular}

Dependent Variable: ASPI

The Table 3 depicts the results of regression analysis. The co - efficient of regression of GDP per capita is 1.757471 , whereas $p$ value is 0.000 . It indicates that if GDP per capita increases by one unit ASPI will increase by 1.757471 . It indicated the impact of independent variable on the dependent variable. According to the results of the regression the R-squared value is 0.833779 and adjusted R-squared is 0.822698 . The P value is 0.0000 which is significance at $1 \%$. The value of $\mathrm{R}$ squared is 0.833779 therefore; it indicates that the model explained 83.3 per cent out of total variations of the dependent variable. It means that approximately $83.3 \%$ of the changes in the dependent variable are described by independent variable. Hence researcher can conclude that economic growth has significant impact on the stock market performance in Sri Lanka.

\subsection{Unitroot Test}

The stationary of the data is checked by employing Augmented Dickey-Fuller (ADF) test in this study because this study used time series data. And the results confirm that the data are stationary and not posing any unit root. 


\section{Table 4. Results of Unit root test}

Null Hypothesis: D(ASPI) has a unit root

Exogenous: Constant

Lag Length: 1 (Automatic - based on SIC, maxlag=3)

\begin{tabular}{llll}
\hline \hline & & t-Statistic & Prob. \\
\hline \hline Augmented Dickey-Fuller test statistic & -4.326873 & \multirow{2}{*}{0.0056} \\
Test critical values: & 1\% level & -4.004425 & \\
& $5 \%$ level & -3.098896 & \\
& $10 \%$ level & -2.690439 & \\
\hline \hline
\end{tabular}

*MacKinnon (1996) one-sided p-values.

Warning: Probabilities and critical values calculated for 20 observations and may not be accurate for a sample size of 14

Null Hypothesis: D(ASPI) has a unit root

Exogenous: Constant

Lag Length: 1 (Automatic - based on SIC, maxlag=3)

\begin{tabular}{llll}
\hline \hline & & t-Statistic & Prob. \\
\hline \hline Augmented Dickey-Fuller test statistic & -4.505202 & \multirow{2}{*}{0.0041} \\
Test critical values: & 1\% level & -4.004425 & \\
& $5 \%$ level & -3.098896 & \\
& $10 \%$ level & -2.690439 & \\
\hline \hline
\end{tabular}

*MacKinnon (1996) one-sided p-values.

Warning: Probabilities and critical values calculated for 20 observations and may not be accurate for a sample size of 14

The ADF's unit root test indicates that data included in this study are stationary at first difference.

\subsection{Residuals Normality Test}

The residual analysis was carried out to prove the model fitness. The below

Figure 2 shows the results of residuals normality test. 


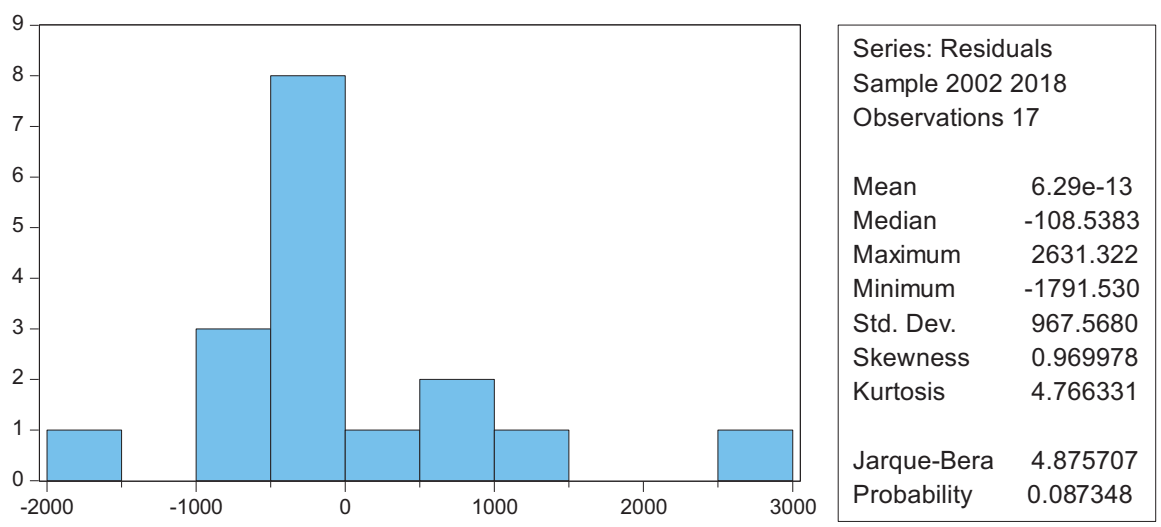

Figure 2 : Residuals Normality Test

The Jarques-Bera test is done for examining the normality specially to see whether data matches a normal distribution. As per the results of residuals normality test the value of Jarque Bera is 4.8757 whereas the P value of Jarque Bera is 0.087348 . Therefore, it can be concluded that the residuals are normally distributed since the Pvalue is 0.087348 .

\section{1.'Conclusion}

The impact of economic growth on stock market performance in Sri Lanka was examined in this study by using annual data from 2002 to 2018 and correlation, and regression analyses were employed as research methodologies. The research findings indicate the existence of strong and positive correlation between economic growth and stock market performance and economic growth significantly impacts on the stock market performance. Economic growth is playing a dominant role in determining the stock market performance. This study, therefore recommend that constant monitoring should be taken place in factors that impact the Gross Domestic Product, to ensure economic stability of Sri Lanka. The nations which have stable macro-economic environment will undergo better and increased share market performance. Appropriate economic policy amendments or abolition can be made based on the findings of researcher on economic growth. Otherwise, people will not interest in investing their money in stock market. It is the responsibility of the Sri Lankan government to take necessary actions to reduce the impact of economic growth to stimulate Sri Lankan economic conditions and make it more efficient and stable. 


\section{References:}

Athapathu, A.R. \& Prabhath, J. (2010). Stock Market Performance and Economic Growth: The Case of Sri Lanka, International Research Conference on Management \& Finance, pp. 83-92.

Bloomberg 2007, Sri Lanka Stocks, Asia Leaders, Tarnished by Fighting (Update1)viewed 2ndOctober2019, <http://www.bloomberg.com /apps/newsfipid=20601109\&sid=aWTGMtLcwOTI\&refer $>$.

Gamlath, G. R. M (2019). Share trading and economic growth in Sri Lanka, SJCC management research review, 7(2), pp. 37-45

Jahfer, A. \& Inoue, T. (2014). Stock market development and economic growth in Sri Lanka, Int. J. Business and Emerging Markets, 6(3), pp.271-282.

Mukit, D., Uddin, M., Islam, M.\& Arif, U. (2014). Stock Market Development and Economic Growth: An Evidence from SAARC Countries. ANVESHAKInternational Journal of Management (AIJM), 3(1). pp. 45-60.

Nijam, H., Ismail, M., \& Musthafa, A. (2011). The impact of macro-economic variables on stock market performance; Evidence from Sri Lanka. Journal of Emerging Trends in Economics and Management Sciences, 6(2), pp. 151157.

Silva, K., Perera, M. \& Silva, N. (2017). Relationship between stock market performance \& economic growth: Empirical Evidence from Sri Lanka, International Conference for Accounting Researchers and Educators, pp. 110.

Rasheedat, P. \& Onabote, A. (2017). stock market and economic growth in Nigeria. International Journal of English Literature and Social Sciences (IJELS), 2(6), pp. 97-106. 